\title{
FACTORS ASSOCIATED WITH SUCCESS AFTER GASTRIC BYPASS SURGERY
}

\author{
A Thesis \\ Presented in Partial Fulfillment of the Requirements for \\ The Degree Master of Science in the \\ Graduate School of the Ohio State University
}

By

Sally Ann Kuzemchak, B.A., R.D.

$* * * * *$

The Ohio State University

2006

Master's Examination Committee:

Dr. Kay N. Wolf, Adviser

Dr. Shirley A. Kindrick

Approved by

Dr. Jenna A. Bell-Wilson

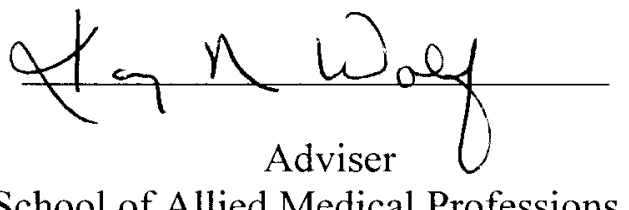

School of Allied Medical Professions 


\begin{abstract}
The purpose of this study was to determine factors associated with success after gastric bypass surgery. The population, 40 adults who underwent gastric bypass surgery at a university medical center, was chosen to study the behaviors of patients in the longterm (5-6 years post-surgery). Subjects were interviewed using a questionnaire that included items about dietary patterns, exercise habits, satisfaction, and quality of life.
\end{abstract} Data were summarized using descriptive statistics.

Forty patients were interviewed, including 35 females and 5 males. Subjects had a mean age of 50.5 years, a mean pre-surgery weight of 330.7 pounds (mean pre-surgery $\mathrm{BMI}=54.0 \mathrm{~kg} / \mathrm{m}^{2}$ ), and a mean post-surgery weight of 236.2 pounds (mean post-surgery $\left.\mathrm{BMI}=38.7 \mathrm{~kg} / \mathrm{m}^{2}\right)$. Twenty $(50 \%)$ were determined to be successful and twenty $(50 \%)$ were determined to be unsuccessful. Although differences in intake and behaviors did not reach statistically significant levels, successful subjects reported eating more frequent meals, as well as more protein and calcium, and were more likely to take a multivitamin, exercise, and follow-up with a health professional other than their physician after surgery. Barriers to weight loss cited included the ability to eat large portions of food, emotional eating, lack of exercise due to health problems, and life stressors. These differences may be of importance and warrant future investigation. 
Dedicated to my husband, Joel and my son, Henry 


\section{ACKNOWLEDGMENTS}

I wish to thank my wonderful adviser, Dr. Kay Wolf, for her support and encouragement over the years and for helping me achieve my professional goals without sacrificing my personal ones.

I thank Dr. Shirley Kindrick for her knowledge, patience, and enthusiasm for the project.

I wish to thank Dr. Jenna Bell-Wilson for valuable writing guidance.

I am grateful to Jill Clutter and Dr. Chris Taylor for technical assistance and statistical knowledge.

I am indebted to Kathie Mulligan, whose counsel has always been appreciated.

I thank Kathy Horton for her help with the patient database and medical records.

I would like to thank everyone at The Ohio State University Center for Wellness and Prevention for allowing me to use their space to conduct interviews.

Lastly, I wish to thank all of my subjects, who shared their opinions, experiences, and stories with me and made this research possible. 


\section{VITA}

March 24, 1972................. Born - Indiana, Pennsylvania

1994.....................................A. English

The Pennsylvania State University

University Park, Pennsylvania

1997 - present.....................Freelance nutrition and health writer

2005 - present.....................Dietitian, Grant Medical Center

Columbus, Ohio

\section{FIELDS OF STUDY}

Major Field: School of Allied Medical Professions

Medical Dietetics 


\section{TABLE OF CONTENTS}

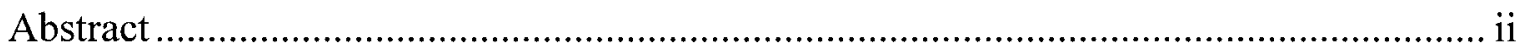

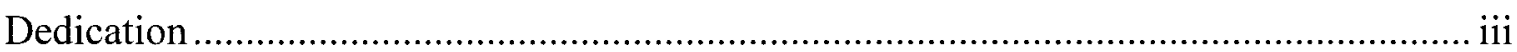

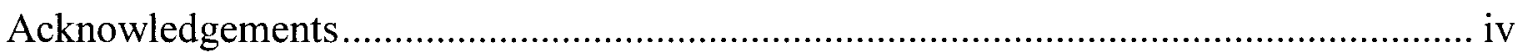

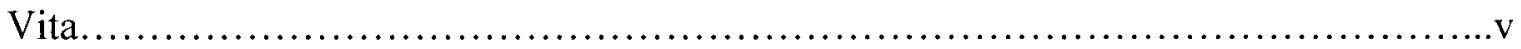

Chapters:

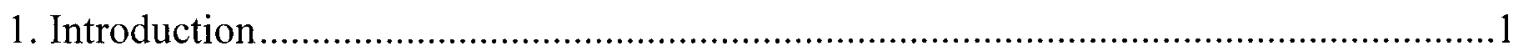

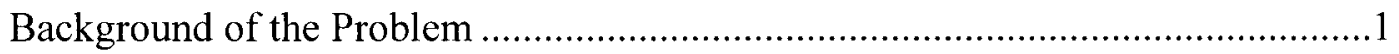

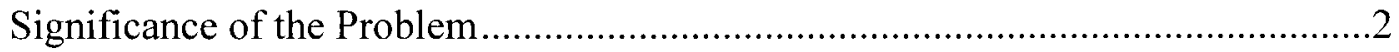

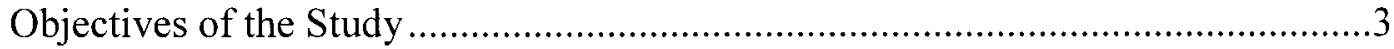

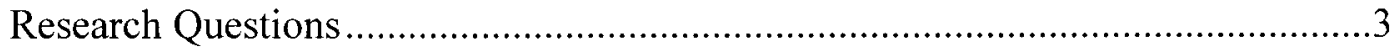

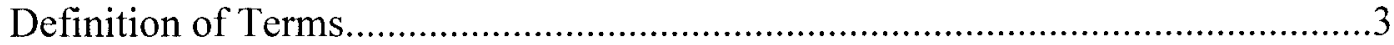

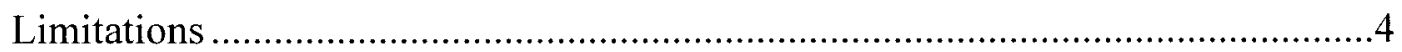

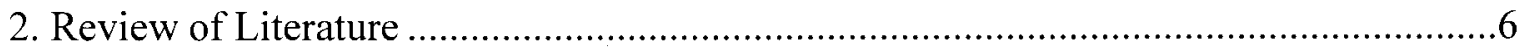

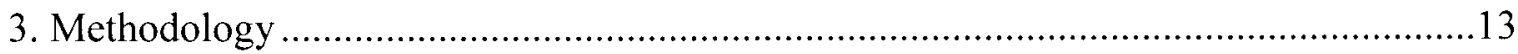

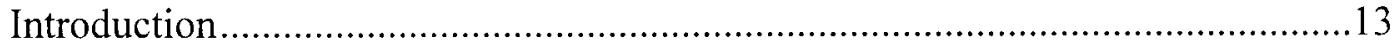

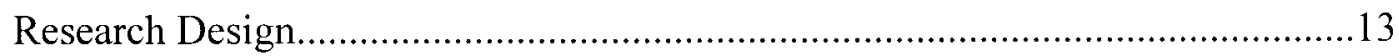

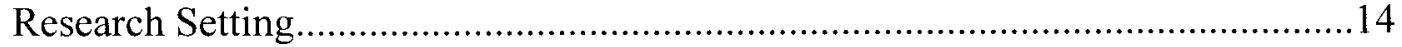

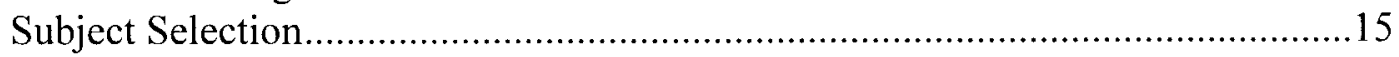

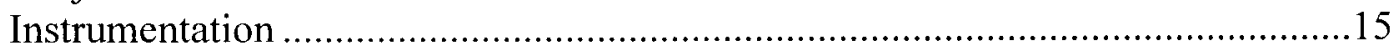

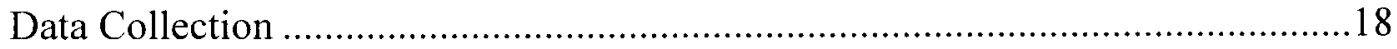

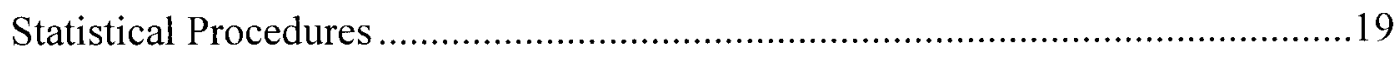


4. Journal Article

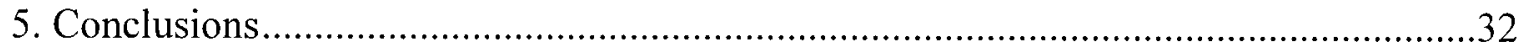

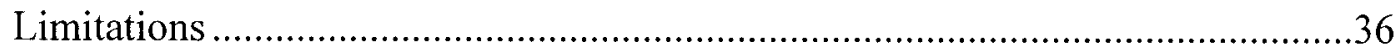

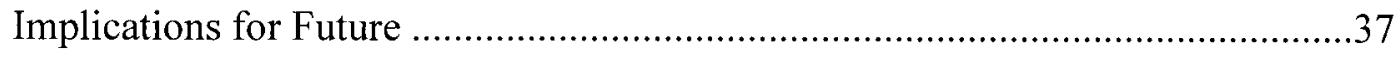

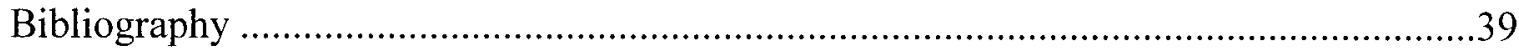

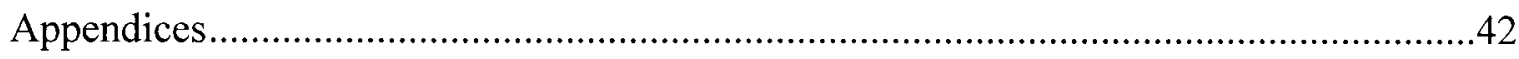

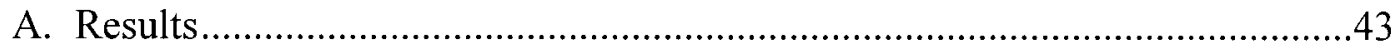

B. Gastric Reduction Outcomes Interview Questionnaire...................................53

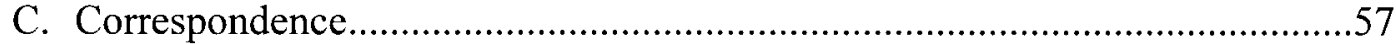




\section{CHAPTER 1}

\section{INTRODUCTION}

\section{BACKGROUND OF THE PROBLEM}

Rates of obesity have more than doubled in the last three decades ${ }^{1}$. Currently, 65.7 percent of adults in the United States are considered overweight or obese ${ }^{2}$. A risk factor for numerous conditions such as diabetes, hypertension, and heart disease, obesity dramatically increases mortality risk. It is estimated that obesity can shorten an individual's life by as much as 20 years $^{3}$. It's even been projected that the overweight and obesity epidemic may cause life expectancy, which was steadily rising, to level off or even decline $e^{4}$. Additionally, the expenses associated with overweight and obesity are substantial for individuals, as well as the health care system, due to more hospitalizations, prescription drugs, and outpatient visits ${ }^{5,6}$. Although the country's population supports a multi-billion-dollar diet industry, failure rates remain discouragingly high. It is reported that very few dieters are ultimately successful at losing a significant amount of weight and maintaining the loss ${ }^{7}$. According to a recent review, major U.S. commercial weight loss programs are associated with high costs, high dropout rates, and a high probability of regaining much of the lost weight ${ }^{8}$.

For severely obese individuals who are at risk for life-threatening health problems but have been repeatedly unsuccessful with traditional dieting efforts, bariatric 
surgery is an option ${ }^{9}$. One of the most common procedures, the Roux-en-Y gastric bypass, can result in the loss of 60-70 percent of excess weight ${ }^{9}$. The prospect of substantial weight loss has made these surgeries extremely popular in recent years. Between 1993 and 2003, the rate of bariatric surgery grew by roughly 600 percent. The American Society for Bariatric Surgery estimates that 171,000 bariatric surgeries were performed in 2005.

\section{SIGNIFICANCE OF THE PROBLEM}

Gastric bypass surgery is considered a "behavioral" surgery because an enormous commitment to lifestyle change must be made for the surgery to be successful over the long term ${ }^{10}$. Some patients either fail to lose the desired amount of weight or eventually regain lost weight. In fact, weight regain is common beginning at two years post-surgery, with many patients' weight eventually remaining 50 percent above their ideal body weight ${ }^{11}$. The factors contributing to this failure rate have not been adequately studied, although poor social support, snacking, alcohol and drug use, and traumatic life events have been suggested as possibilities ${ }^{10}$. Binge eating and low activity level have also been cited $^{11}$. Further research on the factors associated with success after gastric bypass surgery is greatly needed. If these predictive factors for success are identified, health professionals could ensure that patients are given both adequate pre-surgery education and post-operative support in order to ensure better outcomes. 


\section{OBJECTIVES}

The primary objective of this research was to identify factors associated with success after gastric bypass surgery. Specific patient behaviors, life events, and surgical complications were explored as potential factors. It is hoped that the results will help health professionals better equip patients for successful outcomes.

\section{RESEARCH QUESTIONS}

1.) What specific post-operative patient behaviors (intake, speed of diet progression, exercise, medications, and follow-up) are associated with gastric surgery success?

2.) Do negative life events or surgical complications impact whether gastric surgery is successful over the long term?

3.) What is the difference between the intake of high-protein foods, sweets, calciumrich foods, snacks, and supplements in successful and unsuccessful gastric surgery patients?

4.) What are patients' perceived barriers to weight loss after gastric bypass surgery?

\section{DEFINITION OF TERMS}

This section describes the terms and variables used in this study.

Body Mass Index: Weight for height calculated as weight $(\mathrm{kg})$ divided by height $\left(\mathrm{m}^{2}\right)$.

Dumping Syndrome: A syndrome that results from the rapid passage of large amounts of food into the small intestine and characterized by dizziness, flushing, sweating, and weakness. 
Excess Body Weight: The difference between preoperative weight and Ideal Body Weight.

Ideal Body Weight: For women, 100 pounds for the first five feet plus five pounds for each inch over five feet, or 100 pounds minus 2.5 pounds for every inch below five feet. For men, 106 pounds for first five feet plus six pounds for each inch over five feet.

Obesity: The condition of being at least 30 percent above ideal body weight or having a body mass index of more than $30.0 \mathrm{~kg} / \mathrm{m}^{2}$.

Gastric surgery success: For the purpose of this study, success is defined as a weight loss of a minimum of 50 percent of preoperative excess body weight and maintenance of this 50 percent loss since surgery.

Morbid obesity: The condition of being at least 100 pounds over ideal body weight or having a body mass index of at least $40 \mathrm{~kg} / \mathrm{m}^{2}$.

Resting Metabolic Rate: The calories required to maintain vital body functions.

Super obesity: The condition of being at least 200 pounds over ideal body weight or a body mass index of at least $50 \mathrm{~kg} / \mathrm{m}^{2}$.

\section{LIMITATIONS}

One limitation of this study was that many patients were unable to be contacted due to outdated contact information and unlisted phone numbers. Therefore, the sample size may affect generalizability of the results.

Another limitation was that patients who were not successful may have been less inclined to respond than those who were successful. Also, respondents may not have 
been truthful in answering the survey questions and may have provided answers that were socially acceptable but not necessarily accurate. Finally, the sample of patients participating in the research was from one medical center, and therefore the results may not be applicable to those at other facilities. 


\section{CHAPTER 2}

\section{REVIEW OF LITERATURE}

Obesity is a serious health issue that has become a national epidemic. More than 30 percent of U.S. adults are currently obese, defined as being 30 percent above ideal body weight ${ }^{1}$. In addition, more than 65 percent of American adults are either overweight or obese'. Considered to be a major cause of preventable death, obesity increases the death rate for hypertension, coronary artery disease, stroke, and some cancers, and it raises the risk for developing cardiovascular disease and diabetes.

However, for the vast majority of overweight and obese individuals, weight loss has proven difficult through traditional means such as low-calorie diets, exercise, and even pharmacological therapy. Trials of one year or less have shown weight losses of fewer than 22 pounds at one year ${ }^{7}$. In studies with longer-term follow-up, a loss of 20.9 pounds in women and 38.5 pounds in men was seen after 10 years ${ }^{7}$. There is a lack of evidence that major commercial weight loss programs are effective, and they've been shown to be associated with high costs, high drop-out rates, and a high probability of regaining 50 percent or more of lost weight within 2 years ${ }^{8}$.

Considered an option when other weight loss methods have failed, gastric surgery aids in weight reduction by decreasing the capacity of the stomach and limiting oral intake. The expected result of gastric surgery is a weight loss of at least half the 
preoperative excess weight, as well as an improvement in obesity-related health conditions $^{12}$. Two surgical techniques now dominate the field: banded gastroplasty and gastric bypass. In banded gastroplasty procedures, a small pouch is constructed along the lesser curvature of the stomach ${ }^{13}$. Because the pouch is only the size of a person's thumb, patients are unable to ingest large quantities of food at one time. Gastric bypass involves creating a gastric pouch that completely bypasses most of the stomach and the entire duodenum and empties into a portion of the jejunum. This operation leads to weight loss by preventing overconsumption. It also discourages the ingestion of highcalorie liquids and soft foods by inducing subsequent dumping syndrome, which results from the rapid passage of food into the small intestine and causes sweating, dizziness, and weakness.

In the last decade, bariatric surgery has become an increasingly popular option. The American Society for Bariatric Surgery estimates that 171,000 people underwent bariatric surgery in 2005, up from 16,200 in 1994 . According to data from the 2001 and 2002 National Inpatient Survey, hospital costs of laparoscopic gastric bypass were $\$ 19,794$ per case, and costs for open gastric bypass were $\$ 22,313$ per case ${ }^{14}$. Third-party payers, such as insurance companies, currently dictate the criteria for undergoing surgery. This includes a weight of more than 100 pounds above ideal body weight defined by Metropolitan Life Insurance weight charts, serious comorbid illness such as severe diabetes or cardiopulmonary conditions, failed attempts at supervised weight-loss programs, and the absence of substance abuse, psychoses or uncontrolled depression ${ }^{13}$. In addition, it's essential that patients be well informed of surgical risks. A recent 
meta-analysis by Buchwald et al found an operative mortality rate of 0.5 percent among 5644 patients undergoing gastric bypass ${ }^{15}$. The incidence of postoperative complications such as wound infections, leaks from staple line breakdowns, stomal stenosis, and pulmonary problems is estimated to be 10 percent or higher ${ }^{13}$. Other issues include micronutrient deficiencies (such as those of vitamin B12, folate, and iron), persistent vomiting, cholecystitis, and dumping syndrome ${ }^{13}$. A long-term follow-up of 13-15 years found that 68.8 percent of patients still experienced vomiting, and 42.7 percent reported "plugging", which occurs when food becomes lodged in the stomach pouch, causing chest pressure and spasms ${ }^{16}$.

Patients must also be motivated to participate in long-term follow-up. Because obesity is considered to be a chronic disorder-and gastric surgery a weight loss tool not a solution-patients must commit to lifestyle changes. Patients should adhere to a strict post-surgery diet that requires a pureed diet for several weeks followed by a gradual advancement toward a full diet. Patients must then make permanent changes to eating behaviors. These include limiting portions of food to small volumes, eating slowly, emphasizing high-protein foods, and avoiding high-fat, high-cholesterol foods as well as high-sugar foods and beverages ${ }^{17}$.

Gastric surgery has been successful for many patients, resulting in a loss of 50 to 60 percent of excess weight or a reduction in body mass index of $10 \mathrm{~kg} / \mathrm{m}^{2}$ during the first two years postsurgery ${ }^{12}$. MacLean et al followed 143 patients for 5.5 years who underwent gastric bypass and found that 93 percent of obese or morbidly obese patients achieved a body mass index of 35 or below $^{18}$. Fifty-seven percent of super obese patient 
achieved this same body mass index ${ }^{18}$. In a review of 136 studies by Buchwald et al, the mean percentage of excess weight loss was 61.6 percent with gastric bypass ${ }^{15}$.

Although most patients will not be "thin" after surgery, and will remain overweight, the health benefits of the resulting weight loss are substantial. Therefore, it's been noted that successful post-surgical weight loss could be defined as achieving a weight associated with minimal health consequences for the patient ${ }^{19}$. Gastric surgery has been reported to improve conditions such as sleep apnea, glucose intolerance, hypertension, and serum lipid abnormalities ${ }^{13}$. In their study of 82 patients who had Roux-en-Y gastric bypass surgery, Cowan et al noted that subjects lost roughly 30 percent of their initial body weight six to twelve months after surgery and experienced a decrease in elevated fasting blood glucose by 19-28 percent, resolving diabetes in all but one of the patients who previously had diabetes ${ }^{20}$. In addition, the number of subjects with fasting triglyceride levels of 150 and above dropped from 38 to 5 percent postsurgery ${ }^{20}$. In their review, Buchwald et al found that 75.4 percent of patients showed resolution of hypertension, 86.6 percent had resolution of obstructive sleep apnea, and 93.6 percent showed improvement in hyperlipidemia after gastric bypass surgery ${ }^{15}$.

Patients who have been successful also report an improvement in health, body image, self-esteem, and social relationships. Rand et al examined the moods and perceptions of social discrimination before and after surgery in 57 morbidly obese patients $^{21}$. Although 77 percent reported rarely being in "good spirits" pre-surgery, 90 percent reported feeling "cheerful" daily or almost daily after surgery. None of the patients considered themselves attractive before the surgery, but 100 percent said they 
considered themselves attractive after surgery. Patients who are successful report being pleased with the results. In a separate study, Rand et al interviewed 47 patients who had lost 100 pounds or more via surgery and maintained the loss for at least three years. The vast majority of subjects reported that they would prefer to be at normal weight with a major handicap such as deafness, legally blind, or heart disease than be morbidly obese ${ }^{22}$. All of these same patients also stated they'd rather be normal weight than a morbidly obese multi-millionaire $^{22}$. In a survey of 83 subjects one year after gastric bypass surgery, patients also reported an increase in sexual interest, enjoyment, and frequency ${ }^{23}$.

Although it's believed that even small weight losses can yield improvements in health conditions, some patients will fail to lose enough pounds to be considered successful. Currently, successful postoperative weight loss is viewed as at least 50 percent of the patient's excess weight ${ }^{24}$. In a study of 1703 obese subjects, Sjostrom et al noted that 8.8 percent of patients who underwent gastric bypass had a weight loss of less than 5 percent of their initial weight, which would be considered failure ${ }^{25}$. Benotti reports that although anecdotal data suggest that weight control among patients is generally well maintained, the overall failure rate is approximately 20 percent for patients with severe obesity who undergo gastric bypass ${ }^{26}$.

However, exact failure rates among gastric surgery patients are difficult to find. Due to the large numbers of subjects lost to follow-up, many studies lack statistics on failure rates ${ }^{24}$. Though it's been suggested that a postoperative follow-up of at least five years is ideal, there are few studies that include 5 -year results ${ }^{24}$. Whether these patients lost to follow-up represent likely failures with poor weight loss or successful patients 
who no longer think they need professional help is not known, due to conflicting data ${ }^{24}$.

Even patients who initially lose weight post-surgery may regain lost pounds in the years following. While the greatest amount of weight loss occurs in the first year postsurgery, there is a slight trend toward weight regain after $12-18$ months $^{26}$. Hafner and Rogers studied 75 patients with morbid obesity who underwent gastric restriction surgery. They found that the average weight loss totaled 77 pounds in the first postsurgical year, but patients regained an average of five pounds in each of the four years of follow up ${ }^{27}$. Hsu et al concluded that patients who exhibit eating disturbances pre-surgery, such as night eating, excessive snacking, and eating large quantities of sweets, exhibit an improvement in these symptoms that diminishes after two years and leads to weight regain ${ }^{28}$.

Due to gastric surgery's increasing popularity and the costs associated with the procedure, there is much interest in the factors associated with success and failure. According to the data on non-surgical weight loss methods, engaging in exercise, having a supportive spouse, and frequent follow-up predicted weight loss, whereas food binges and eating in response to emotions were linked to weight gain or lack of substantial weight $\operatorname{loss}^{29}$. However, there is a lack of data on predictors of success after bariatric surgery. In a study of 100 patients, those considered successful avoided carbonated beverages, exercised regularly and took daily multivitamins, while those considered unsuccessful reported a lack of exercise, poorly balanced meals, and frequent grazing or snacking $^{30}$. It has been noted that patient knowledge deficits, such as ignoring instructions on the required postoperative eating habits, may also lead to poor 
outcomes $^{31}$. When Madan and Tichansky retested patients on preoperative education up to one year after surgery, they found that one of the most common incorrect answers was "false" to the question "Obesity surgery is basically an aid to dieting: it does not mean that you will lose weight no matter what you eat or do"32.

In a review of 29 studies, Herpertz et al noted that patients with a high pre-surgery intake of sweets, chips, and soft drinks could have a higher risk for failure ${ }^{33}$. Binge eating and low activity level have also been mentioned ${ }^{12}$. Attitude or psychologic influences, such as disruptive life events, have been cited. Kral points to snacking, alcohol and drug use, and childhood abuse as possibilities ${ }^{10}$. Hafner et al, who found that marital dissatisfaction increased among husbands whose wives underwent the procedure, speculates that lack of spousal support may contribute to weight regain ${ }^{27}$. 


\section{CHAPTER 3}

\section{METHODOLOGY}

\section{INTRODUCTION}

This chapter describes the design of the study, research setting, subject selection, instrumentation used, and statistical procedures.

\section{RESEARCH DESIGN}

The purpose of this descriptive study was to identify factors associated with success after gastric bypass surgery. In order to identify these factors, a survey was conducted of patients who underwent gastric bypass surgery at a university medical center in 1999. An in-person survey was originally attempted in hopes of gaining greater detail, as well as to obtain an accurate current weight. However, due to lack of interest in coming to the interview site, surveys were also conducted by telephone. A total of 12 surveys took place in person, and 29 surveys were conducted by telephone (one telephone survey was not included in the data analysis when it was discovered that the subject did not have gastric bypass surgery). An incentive was offered to those taking the survey inperson. The incentive consisted of a free resting metabolic rate (RMR) measurement, a breathing test that measures resting caloric needs, which was conducted at the time of the survey. Subjects' medical and clinical records were also reviewed to obtain subjects' 
heights and preoperative weights. Permission was obtained from the Institutional Review Board of The Ohio State University to conduct the study.

\section{RESEARCH SETTING}

The university medical center's weight management program, which began performing gastric bypass surgery in 1991, includes a multidisciplinary team of surgeons, physicians, nurses, dietitians, and psychologists. Prior to approving potential candidates for the bariatric surgery, the team performs a series of evaluations on each patient including a medical assessment, nutritional evaluation, psychological evaluation, and surgical consultation.

The medical assessment consists of a complete medical history and physical. The purpose is to identify any comorbid conditions such as diabetes and high blood pressure which necessitate bariatric surgery and also contraindications for the surgery, including end stage renal disease, heart disease, or an active eating disorder. The nutritional evaluation examines current dietary patterns and past attempts at weight loss. The psychological evaluation consists of a shortened version of the Minnesota Multiphasic Personality Inventory. The objective is to measure compliance, as well as identify patients with eating disorders, untreated depression, and other problems that could interfere with weight loss maintenance. Finally, patients meet with the staff surgeon to discuss the procedure as well as the surgical risks. Patients are encouraged to follow-up after surgery with the surgeon and dietitian. 


\section{SUBJECT SELECTION}

The target population in this study consisted of patients who received gastric bypass surgery. The sample for this study was patients who underwent gastric bypass surgery in 1999 at a Midwestern university medical center. The purpose of using a sample from 1999 was to observe long-term results from surgery. It's been noted that a "honeymoon" phase occurs immediately after the procedure, in which patients exhibit high motivation and lose weight quickly. According to the program's database, 327 gastric bypass surgeries were performed in 1999. However, due to technical problems with the database, a list of only 97 of these patients was available. The sample consisted of all 97 patients.

\section{INSTRUMENTATION}

The method of data collection used in this study was an interview. The instrument used was a preexisting questionnaire, the Gastric Reduction Outcomes Interview Questionnaire (Appendix B), which was revised to include questions on specific behaviors post-surgery, such as time spent on a pureed diet. There were four sections that included information about nutrition, patient behaviors, satisfaction, and quality of life. All sections included both interval and open-ended questions.

The first section, "Nutrition", included six questions that were designed to answer the research question "What specific post-operative patient behaviors are associated with gastric surgery success?" The first question asked how many meals subjects eat per day, with options ranging from 1 to 5-6 per day. The second asked how long subjects take to 
eat meals, with options of 0-9 minutes, 10-19 minutes, or 20 minutes or more. The third, an open-ended question, asked what high protein foods they eat or drink most often. A follow-up question asked "How often?" with choices of 1-5 sources per day. The fourth item asked what supplements they take, with options of "Don't take", "Not at recommended level", and "Prenatal/Equivalent". The fifth item was an open-ended question about what kinds of supplements they take. The last item asked what calciumrich foods they consume, with a follow-up question of "How many sources per day", with choices of $0-1,2$ or 3 sources per day.

The second section was titled "Behaviors", and all items were also designed to answer the research questions "What specific post-operative patient behaviors have the greatest impact on whether gastric surgery is successful over the long term?" The first item inquired about the length of time patients spent on the Step 2 Diet (a texturemodified diet), with options ranging from 2-8 weeks. The next two items were openended questions that asked "Have there been any changes in medication since surgery?" and "Are you taking any new medications since surgery?" The fourth question asked how often subjects exercise, and options range from "never" to "daily"; a follow-up question asked how many minutes do they exercise at a time, with choices of $0-15,16-30$, or 31 60 minutes. The next question asked "How many glasses of the following beverages do you drink each day?" and included water, regular soda, juice, beer, alcohol, and wine. The next questions asked how often subjects dine out in restaurants; options ranged from "never" to "daily". The next two items were open-ended questions: "Do you incorporate sweets into your diet? If yes, what kinds?" and "What other types of snacks do you eat?" 
The last question in the section asked whether subjects sought any type of follow-up with a health care professional after surgery (excluding regular exams with their physician), with a follow-up question asking what type of health professional.

The next section, "Satisfaction" included three items. The first asked "How satisfied were you with the nutrition education you received presurgically?" and options ranged from "extremely dissatisfied" to "extremely satisfied". The next item asked for current weight, and this was used to classify the subject as successful or not successful. Participants who completed the survey in-person were weighed by the study coordinator on a calibrated scale at the interview site. Those who completed the survey by phone were asked to state their current weight. The third question asked "What do you feel has been a barrier to weight loss?" This item is designed to answer the research question: "What are patients' perceived barriers to weight loss after gastric surgery?"

In the final section, "Quality of Life", the first two questions were designed to answer the research question, "Do traumatic life events or surgical complications impact whether gastric surgery is successful over the long term?" These included: "Have you experienced any negative life events since your surgery (such as a divorce, death of a loved one, loss of job for self or spouse) with a follow-up question, "If so, what type?" and "Did you experience any problems or complications post-surgery?" with a follow-up question asking the type of complication(s). The final question asked "Do you feel that you had an adequate amount of support in your life post-surgery?" with options of yes or no. 


\begin{tabular}{|c|c|}
\hline VARIABLE & MEASURE (Question \#) \\
\hline Intake & $1-7,12-16$ \\
\hline Speed of Diet Progression & 8 \\
\hline Exercise & $10-12$ \\
\hline Medications & 9 \\
\hline Follow-Up & 17 \\
\hline Satisfaction with Pre-Surgical Nutrition \\
Education & 18 \\
\hline Perceived Barriers & 20 \\
\hline Negative Life Events & 21 \\
\hline Post-Operative Complications & 22 \\
\hline Support & 23 \\
\hline
\end{tabular}

\section{Table 1. Variables included in gastric outcomes questionnaire}

\section{DATA COLLECTION}

A staff member of the weight management program compiled a list of patients who received gastric bypass surgery in 1999. Subjects' addresses and phone numbers were retrieved from the patient database. Subjects were contacted by the study coordinator via a letter inviting their participation in the study. As an incentive, a free resting metabolic rate measurement at the university's wellness center was offered to those who agreed to participate. If a response was not received after four weeks, three attempts were made to contact each subject by phone. Phone calls were made on a studydesignated cell phone. If contact was still not made with the subject, a follow-up postcard was sent asking the subject to schedule an interview. Subjects scheduled interview times by either calling the study coordinator on the study cell phone or emailing the principle investigator. 
For in-person interviews, the surveys and the RMR measurements were performed at the CWP by the study coordinator in a space that offered confidentiality of survey answers and RMR results. Subjects' responses to the questions were recorded on the questionnaire by placing an " $\mathrm{X}$ " in the appropriate boxes and writing in the responses for the open-ended questions. After each survey, the RMR measurement was performed by the study coordinator. Each survey and RMR measurement was completed in less than 45 minutes. Phone interviews were conducted on the study cell phone in a confidential space. When subjects agreed to participate in the study, permission was requested to access their medical records.

\section{STATISTICAL PROCEDURES}

The data was coded and entered into a database. The Statistical Package for the Social Sciences (SPSS 14.0) program was used to generate frequency and descriptive statistics. Chi-Square significance tests were used to test the hypothesis of no association. 


\section{CHAPTER 4}

\section{JOURNAL ARTICLE}

Factors Associated With Success After Gastric Bypass Surgery

Sally A. Kuzemchak, B.A., RD, Kay N. Wolf, Ph.D, RD, Shirley A. Kindrick, Ph.D, RD, Jenna A. Bell-Wilson, Ph.D., RD

Background: There is evidence of a high success rate immediately after gastric bypass surgery, but the surgery's effect on weight in the long term and the factors associated with long-term success are unknown. Due to gastric surgery's increasing popularity and the costs associated with the procedure, there is much interest in the factors associated with success and failure. An understanding of the behaviors and experiences of successful patients after gastric bypass surgery could also equip patients for better outcomes. The purpose of this descriptive study was to determine the factors associated with successful weight loss and maintenance of weight loss six years post-gastric bypass surgery.

Methods: Forty patients who underwent gastric bypass surgery in 1999 were interviewed using a questionnaire. Subjects' medical records were also reviewed to obtain height and pre-surgery weight.

Results: Thirty-five females and 5 males completed the survey. Subjects had a mean age of 50.5 years, a mean pre-surgery weight of 330.7 pounds, and a mean post-surgery 
weight of 236.2 pounds. Twenty (50\%) were determined to be successful and twenty $(50 \%)$ were determined to be unsuccessful. There were no statistically significant differences found in food intake, exercise habits, degree of follow up, or incidence of negative life events between successful and unsuccessful subjects. Among those classified as unsuccessful, barriers to weight loss cited included the ability to eat large portions of food, emotional eating, lack of exercise due to health problems, and life stressors.

Conclusion: Little is known about the factors associated with long-term weight loss and maintenance of weight loss after gastric bypass surgery. Factors such as beverage consumption, intake of sweets, eating out, exercise, and negative life events have all been suggested as possible predictors of success after surgery. Although they did not reach level of significance, differences were seen among some variables such as exercise habits, vitamin intake, protein intake, and dining out that may be important and warrant further investigation.

\section{Introduction}

The United States is currently experiencing an epidemic of obesity, a risk factor for numerous conditions such as diabetes, hypertension, and heart disease, which dramatically increases mortality risk. Additionally, it is reported that very few dieters are successful at losing a significant amount of weight and maintaining the loss for several years. Bariatric surgery is an increasingly popular option for obese individuals who are at risk for life-threatening health problems but have been repeatedly unsuccessful with 
traditional dieting efforts. Between 1993 and 2003, the rate of bariatric surgery grew by roughly 600 percent. One of the most common procedures, the Roux-en-Y gastric bypass, can result in the loss of two-thirds of excess weight within the first two years ${ }^{1}$.

Although gastric bypass surgery has been reported to have a high success rate, some patients either fail to lose the desired amount of weight or eventually regain lost weight. Weight regain is common beginning at two years post-surgery, and many patients' weight eventually remains 50 percent above their ideal body weight ${ }^{2}$. Because an enormous commitment to lifestyle change must be made for the surgery to be successful over the long term, it is considered a "behavioral" surgery ${ }^{3}$. Some of these lifestyle factors have been suggested as possible predictors of weight loss after surgery, such as snacking and alcohol use, in addition to quality of life factors such as social support and traumatic life events ${ }^{2}$. Binge eating and low activity level have also been $\operatorname{cited}^{2}$. However, these factors have not been adequately studied. The objective of this research was to identify factors that are associated with successful weight loss and maintenance of weight loss after gastric bypass surgery.

\section{Materials and Methods}

A survey was conducted of patients who underwent gastric bypass surgery at a mid-western medical center in 1999. Contact with 97 patients was attempted, but correct contact information was available for only 62 patients. A total of 40 subjects were surveyed. Twelve interviews took place in person, and twenty-eight were conducted by telephone. Subjects' medical records were also reviewed to obtain height and pre-surgery 
weight. The study was approved by the Institutional Review Board of our institution.

The instrument used was a preexisting questionnaire that included items about nutrition, patient behaviors, satisfaction and quality of life and was revised to include specific post-surgery behaviors, such as time spent on a pureed diet. It was developed by a group of dietetics professionals and used in previous research. All sections included both interval and open-ended questions.

Once the surveys were completed, subjects were classified as successful or unsuccessful based on their preoperative and current weights. Success was defined as the loss of at least 50 percent of excess weight and maintenance of weight loss. The Statistical Package for the Social Sciences (SPSS) program was used to generate frequency and descriptive statistics.

\section{Results}

The forty patients interviewed included 35 females and 5 males, with a mean age of 50.5 years. The patients had a mean pre-surgery weight of $150.3 \mathrm{~kg}$ (mean pre-surgery $\mathrm{BMI}=54.0 \mathrm{~kg} / \mathrm{m}^{2}$ ) and a mean post-surgery weight of $107.4 \mathrm{~kg}$ (mean post-surgery $\mathrm{BMI}=$ $\left.38.7 \mathrm{~kg} / \mathrm{m}^{2}\right)$. Of the forty, $20(50 \%)$ were determined to be successful and $20(50 \%)$ were determined to be unsuccessful.

Table 1 summarizes intake among the groups. Fifty percent of successful subjects $(n=10)$ and 80 percent of unsuccessful subjects $(n=16)$ reported consuming three or fewer meals (or "mini-meals") per day. The majority of successful ( 80 percent; $n=16$ ) and unsuccessful ( 75 percent; $n=14$ ) subjects reported taking 19 or fewer minutes to eat a 
meal. Fifty percent of successful subjects $(n=10)$ and 35 percent of unsuccessful subjects $(n=7)$ reported eating three or more protein sources per day.

Thirty-five percent of successful subjects ( $\mathrm{n}=7$ ) and 25 percent of unsuccessful subjects $(n=5)$ reported eating out twice a month or less. The majority of successful subjects ( 75 percent; $n=15$ ) and unsuccessful subjects ( 90 percent; $n=18$ ) reported incorporating sweets into their diets. Chocolate and cookies were the two most frequently cited sweets eaten by both groups. Subjects were also asked about their snacking habits. The most frequently cited snacks among successful subjects were (in order of frequency cited) chips, popcorn, yogurt, vegetables, and protein (such as cheese, meat sticks and hard-boiled eggs). Unsuccessful subjects named chips, cheese and crackers, sweets, and fruit as their top snacks.

Thirty-five of successful subjects ( $n=7)$ and 20 percent of unsuccessful subjects $(n=4)$ report taking a daily multivitamin at the recommended post-surgery level, typically a prenatal vitamin. Twenty-percent of both groups $(n=8)$ reported taking no multivitamin. Fifty-five percent of successful subjects $(n=11)$ and 60 percent of unsuccessful subjects $(n=12)$ reported taking additional supplements. The most common supplements used by subjects were iron $(n=13)$, calcium $(n=13), B 12(n=8)$, potassium $(n=5)$, and vitamin $E$ $(n=5)$.

Subjects were asked how long they remained on the Step 2 Diet, a pureed-foods diet prescribed after surgery. Eleven successful subjects (68.8 percent) and 15 unsuccessful subjects ( 88.2 percent) reported spending 2-4 weeks on the diet. Three successful subjects (18.8 percent) and two unsuccessful subjects (11.8 percent) reported 
spending 6-8 weeks on the diet. Seven subjects could not recall the length of time spent on the diet.

There were no statistically significant differences in beverage consumption between successful and unsuccessful subjects. The mean water consumption among successful subjects was 4.9 glasses per day and 4.1 glasses per day for unsuccessful subjects. Successful subjects consumed .2 glass of regular soda, 1.2 glass diet soda, .2 glass juice, .1 glass beer, and 0 glasses alcohol or wine per day. Unsuccessful subjects took in .6 glass regular soda, 1.5 glasses diet soda, .3 glass juice, 0 glasses beer, .2 glass alcohol, and 0 glasses wine per day.

Table 2 summarizes the findings regarding exercise behaviors. Fifty-five percent of successful subjects $(n=11)$ and 40 percent of unsuccessful subjects $(n=8)$ reported exercising. Twenty percent of successful subjects $(n=4)$ and ten percent of unsuccessful subjects $(n=2)$ reported exercising daily. Of the 11 successful subjects and eight unsuccessful subjects who exercised, most reported exercising for 16-30 minutes. Walking was the most common form of exercise performed by all subjects $(n=13)$, followed by working out at a fitness center $(n=3)$, doing exercise videos $(n=2)$, and riding an exercise bike $(\mathrm{n}=2)$.

Subjects were asked whether they had sought any type of follow up since surgery, not including visits with their physician. Fifty-five percent of successful subjects $(n=11)$ and 45 percent of unsuccessful subjects $(n=9)$ reported seeking follow up. Among both groups, type of follow up mentioned included working with a registered dietitian $(n=11)$, attending a support group $(\mathrm{n}=8)$, and seeing a therapist or counselor $(\mathrm{n}=3)$. Additionally, 
90 percent of both groups (successful: $n=18$; unsuccessful: $n=18$ ) reported that they were extremely satisfied or satisfied with the nutrition education they received before surgery.

Seventy percent of successful subjects $(n=14)$ and 75 percent of unsuccessful subjects $(n=15)$ reported experiencing negative life events, such as death of a loved one or a divorce, since surgery. Sixty-percent of successful subjects $(n=12)$ and 50 percent of unsuccessful subjects $(n=10)$ reported having complications after surgery, such as infection or rehospitalization. Ninety percent of both groups (successful $n=18$; unsuccessful $n=18$ ) reported having an adequate amount of social support in their lives after surgery.

Subjects were asked to describe any perceived barriers to weight loss after surgery. Among those classified as unsuccessful, some of the reasons cited included the ability to eat big portions of food, emotional eating, lack of exercise due to health problems, and life stressors. 


\begin{tabular}{|c|c|c|c|}
\hline Intake Variable & & $\begin{array}{c}\text { Successful } \\
\text { n }(\%)\end{array}$ & $\begin{array}{c}\text { Unsuccessful } \\
\text { n (\%) }\end{array}$ \\
\hline \multirow[t]{2}{*}{ Number of Meals } & 1-3/day & $10(50)$ & $16(80)$ \\
\hline & 4 or more & $10(50)$ & $4(20)$ \\
\hline \multirow[t]{2}{*}{ Length of time to eat a meal } & 0-19 minutes & $16(80)$ & $15(75)$ \\
\hline & 20 or more & $4(20)$ & $5(25)$ \\
\hline \multirow[t]{2}{*}{ Frequency of protein intake } & $1-2$ sources/day & $8(40)$ & $12(60)$ \\
\hline & 3 or more/day & $10(50)$ & $7(35)$ \\
\hline \multirow[t]{2}{*}{ Frequency of calcium intake } & $0-1$ sources/day & $8(42.1)$ & $12(60)$ \\
\hline & 2 or more & $11(57.9)$ & $8(40)$ \\
\hline \multirow[t]{3}{*}{ Frequency of dining out } & Daily & $1(5)$ & $2(10)$ \\
\hline & At least twice/week & $12(60)$ & $14(70)$ \\
\hline & Twice/month or less & $7(35)$ & $4(25)$ \\
\hline \multirow[t]{2}{*}{ Incorporation of sweets } & Yes & $15(75)$ & $18(90)$ \\
\hline & No & $5(25)$ & $2(10)$ \\
\hline
\end{tabular}

${ }^{*}$ n successful $=20 ; * * n$ unsuccessful $=2$

Success was defined as a loss of at least 50 percent of excess pre-surgery weight and maintenance of the loss.

'Chi-Square with 6 degrees of freedom $=8.599 ; \mathrm{p}=.197$

${ }^{2}$ Chi-Square with 2 degrees of freedom $=1.293 ; p=.524$

${ }^{3}$ Chi-Square with 4 degrees of freedom $=5.343 ; \mathrm{p}=.254$

${ }^{4}$ Chi-Square with 3 degrees of freedom $=2.776 ; p=.427$

${ }^{5}$ Chi-Square with 4 degrees of freedom $=1.762 ; p=.779$

${ }^{6} \mathrm{Chi}-$ Square with 1 degree of freedom $=1.558 ; \mathrm{p}=.212$

Table 1. Intake of meals, protein, calcium, and sweets among subjects 


\begin{tabular}{|l|l|c|c|}
\hline & & Successful n (\%) & Unsuccessful n (\%) \\
\hline Number who exercise & & $11(55)$ & $8(40)$ \\
\hline Exercise frequency & Never & $10(50)$ & $12(60)$ \\
\hline & Once/week & $0(0)$ & $4(20)$ \\
\hline & $2-3$ times /week & $6(30)$ & $2(10)$ \\
\hline & Daily & $4(20)$ & $2(10)$ \\
\hline Duration of exercise & $0-15$ minutes & $2(18.2)$ & $1(12.5)$ \\
\hline & $16-30$ minutes & $7(63.6)$ & $5(62.5)$ \\
\hline & $31-60$ minutes & $2(18.2)$ & $2(25)$ \\
\hline
\end{tabular}

${ }^{*} \mathrm{n}$ successful $=20 ;{ }^{* *} \mathrm{n}$ unsuccessful $=2$ (Success was defined as a loss of at least 50 percent of excess pre-surgery weight and maintenance of the loss.)

${ }^{1}$ Chi-Square with 1 degree of freedom $=.902 ; p=.342$

${ }^{2}$ Chi-Square with 3 degrees of freedom $=6.848 ; p=.077$

${ }^{3}$ Chi-Square with 2 degrees of freedom $=.198 ; p=.906$

Table 2. Exercise habits among subjects

\section{Discussion}

Although gastric bypass surgery is growing in popularity and is associated with substantial health care costs, little is known about the factors associated with long-term weight loss and maintenance of weight loss after surgery. Though factors such as beverage consumption, intake of sweets, eating out, exercise, and traumatic life events have been proposed as possible predictors of degree of success after gastric bypass surgery, no significant differences in these variables were found in the present study. However, it is possible that the sample size limited the ability of strong trends to emerge. Loss of patients to follow-up has been a recurring problem in research on bariatric surgery, and the current study was no exception.

Though no significant differences occurred, there were practical differences in 
behaviors between the groups that may be important. Successful patients reported consuming more meals (or "mini-meals") and more protein per day. Eating small, frequent meals may help prevent overeating and drops in metabolic rate. Because protein absorption is compromised after surgery, frequency intake of protein is recommended to avoid deficiency. Protein is also believed to induce fullness. Successful subjects ate out less frequently and were more likely to exercise and take a multivitamin than were unsuccessful subjects. Fewer successful subjects reported incorporating sweets into their diet than unsuccessful subjects. More successful subjects sought follow-up than unsuccessful as well.

Patients' perceived barriers to weight loss or maintenance of weight loss were also revealed. The most commonly cited barrier was the ability to consume more food than subjects thought they could. Gastric bypass surgery is designed to limit consumption by shrinking the stomach pouch, but some subjects reported that this portion-limiting effect gradually diminished, allowing them to overeat. Also, one subject complained that tempting foods she thought would cause dumping syndrome and therefore remain offlimits (such as sweets) no longer caused problems.

This research did have some limitations, including a low accessibility to potential subjects. Many patients were unable to be contacted due to outdated contact information and unlisted phone numbers, and the sample size may affect generalizability of the results. In addition, previous research has demonstrated underreporting of intake among obese populations, and this could have occurred in the present study. Respondents may not have been truthful in answering the survey questions and may have provided answers 
that were socially acceptable but not necessarily accurate. Determination of which patients were successful may also have been negatively affected by patients' self-reported weights. A final limitation of the current study is that the patients participating in the research were from one medical center, and therefore the results may not be applicable to those at other facilities.

Gastric bypass surgery is not foolproof. Some patients simply fail to lose a significant amount of weight, or regain weight after surgery. In the current study, failure rate was 50 percent. Although this study did not find any statistically significant differences between successful and unsuccessful patients five years after gastric bypass surgery, the results should not hinder further investigation or frustrate health professionals who work with these patients and advocate for lifestyle modification behaviors such as reducing portions or seeking follow-up. Clearly, there are differences between successful and unsuccessful patients with regards to energy balance, and there is a critical need to investigate these factors in order to improve long-term outcomes.

The study does direct attention at the important role that dietetics professionals can and should play after surgery. There is evidence that patients forget pre-surgery nutrition education ${ }^{4}$, which the current study also revealed. For example, two subjects were unable to identify foods that contain protein. Subjects also expressed some confusion over follow-up post-surgery: One unsuccessful subject noted that her surgeon told her she never needed to come back once she lost weight, and another successful subject said she felt "cast out into the wind" after surgery. Since gastric bypass surgery requires lifelong changes to behavior, patient should be directed to dietetics professionals 
not only in the months following surgery, but also on an ongoing basis in the long-term.

Further study is needed in this area. It is possible that the small sample size in the current investigation did not allow trends to emerge. It is also possible that the study was not able to adequately measure intake differences between the groups, and future research might benefit from a food frequency component or other measures of intake. Another factor that the current study did not examine was weight regain. Many subjects noted that they had regained some or all of the weight they initially lost after surgery. It may be helpful to study when weight regain typically happens for these patients and whether particular behaviors or events trigger this regain.

Finally, future researchers may want to explore the concept of personal motivation. Perhaps there is a discrepancy in the level of self-efficacy between the successful and unsuccessful patients. If some patients believe they have the ability to lose weight and maintain the loss, they may be more likely to be successful in the longterm. Asking patients to rate their level of confidence as well as the level of importance of losing weight and maintaining the loss may uncover importance differences.

\section{REFERENCES}

1. U.S. Department of Health and Human Services, National Institutes of Health NIH Publication No. 01-4006 Dec. 2001. Available from: www.http://www.niddk.nih.gov/health/nutrit/pubs/gastric/gastricsurgery.htm. Accessed August 25, 2004.

2. Hsu L et al. Nonsurgical factors that influence the outcome of bariatric surgery: A review. Psychosom Med. 1998;60:338-346.

3. Kral G. Selection of patients for anti-obesity surgery. International Journal of Obesity. 2001;25: S107-S112.

4. Madan AK and Tichansky DS. Patients postoperatively forget aspects of preoperative patient education. Obesity Surgery. 2005;15:1066-1068. 


\section{CHAPTER 5}

\section{CONCLUSIONS}

Although gastric bypass surgery has been shown to have a high success rate within the first few years post-surgery, less is known about the factors related to longterm success. The results of this study reveal behaviors and experiences of gastric bypass patients six years post-surgery. Although the current investigation did not find statistically significant differences between successful and unsuccessful patients, it is possible that the small sample size limited the ability of strong trends to emerge. Forty subjects completed the study, which represented a 65 percent response rate of the accessible population. Loss of patients to follow-up has been a recurring problem in research on bariatric surgery, and the current study was no exception.

However, although the results did not reach level of significance, there were small variations in several behaviors between the groups that may be important. Fifty percent of successful subjects $(n=10)$, but only twenty percent of unsuccessful subjects $(n=4)$, reported eating four or more meals (or "mini meals") per day. Eating six small meals a day is the current recommendation to patients to ensure modest portions and prevent the metabolic rate from slowing. In addition, in research on people who have successfully maintained significant weight loss through non-surgical methods, most report consuming 
nearly five meals per day ${ }^{34}$.

Fifty percent of successful subjects $(n=10)$ and thirty-five percent of unsuccessful subjects $(n=7)$ reported eating three or more protein sources per day. Patients are encouraged to consume a protein source at all meals and snacks, as protein absorption is compromised when much of the stomach is bypassed. Protein may also help induce fullness. Fifty-eight percent of successful subjects $(n=11)$ and forty percent of unsuccessful subjects $(n=8)$ reported eating two or more calcium sources per day. Some studies have shown that calcium may aid in weight $\operatorname{loss}^{35,36}$. Though high-sugar foods have a tendency to cause dumping syndrome after surgery and are discouraged in order to prevent excess caloric consumption, the majority of both groups ( $75 \%$ successful; $90 \%$ unsuccessful) said they incorporate sweets into their diet. It may have been beneficial to inquire about the frequency of eating sweets, since this would have a potentially significant impact on caloric consumption.

Thirty five percent $(n=7)$ of successful subjects and twenty-five percent of unsuccessful subjects $(n=4)$ reported eating out twice a month or less. For gastric bypass patients, limiting the frequency of dining out is one valuable strategy for controlling caloric consumption, since most restaurants typically serve large portions of high-calorie food. Frequent dining out has been shown in previous research to lead to overall higher calorie consumption in the general population ${ }^{37}$.

Unsuccessful subjects consumed just slightly more regular soda per day than successful subjects (.6 glass per day vs. .2). There was less difference in daily juice consumption (unsuccessful $=.3$; successful $=.2$ ). Beverage intake is another strong 
indicator of calorie intake, and frequent consumption of high-calorie liquids can result in weight gain. This is especially true for gastric bypass patients, since stomach capacity is not limited by liquids. It is possible that the current study did not uncover more differences in this area because questions were not asked about other high-calorie drinks, such as fruit punches, energy drinks, and sweetened tea, which some subjects voluntarily reported consuming.

In the current study, fifty-five percent of successful subjects $(n=11)$ and forty percent of unsuccessful subjects $(n=8)$ reported exercising. Twenty percent of successful subjects $(n=4)$ and 10 percent of unsuccessful subjects $(n=2)$ reported exercising daily. Walking was the most favored of all activities $(n=13)$. However, most exercisers in both the successful and unsuccessful groups report exercising for only 16-30 minutes, which is below current federal recommendations of at least 60 minutes on most days to manage body weight ${ }^{38}$. Data from previous studies on successful weight loss maintainers also suggests that 60 minutes per day is optimal at maintaining substantial weight $\operatorname{loss}^{34}$. Previous research has found exercise to be an integral part of a weight control program, possibly due to its ability to decrease appetite and slow the decline of metabolic rate ${ }^{29}$. Fifty-five percent of successful subjects $(n=11)$ and forty-five percent of unsuccessful subjects $(n=9)$ reported seeking some type of follow-up after surgery, not including appointments with their physician. Meeting with a dietitian and attending support groups were the most common forms of follow-up in each group. However, subjects also expressed confusion and frustration on the topic of follow-up. One unsuccessful subject said she was under the impression that she didn't need to come back 
once she lost weight. Another successful subject reported she her surgeon said she did not need to return, and that she felt "cast out into the wind" after surgery. If physicians are not currently encouraging patients to follow-up with a dietetics professional, this represents a critical area for improvement. The program in our investigation recommends that patients follow-up with a dietitian several times in the first year after surgery, and then annually. They also encourage patients to join behavior change or exercise programs and seek the help of a counselor if emotional eating is a problem. Follow-up has been shown to be significantly associated with greater weight reduction after an organized weight loss program ${ }^{29}$. The drop in follow-up generally seen among patients after gastric surgery may be due in part to underestimating the long-term consequences of the surgery ${ }^{40}$.

Subjects reported a variety of barriers to weight loss. Several subjects reported they could eat much larger portions than they hoped they could. One subject stated that she didn't think the surgery worked because her stomach pouch seemed too big. Although gastric bypass surgery does greatly reduce the capacity of the stomach pouch, it is possible to enlarge the pouch by consistently overeating. Another subject reported that because she experiences nausea if her stomach becomes empty, she constantly grazes on food. Two subjects noted that their bodies seemed to adapt to foods they thought would cause dumping syndrome (such as sweets), so these foods became tempting again. Four subjects cited emotional eating as a barrier to weight loss. One subject said she did not initially lose as much weight as she had hoped, which negatively impacted her motivation. Seven subjects stated that health problems made exercise difficult or 
impossible and contributed to lack of weight loss.

The majority of subjects $(n=29)$ reported experiencing a negative life event in the five years since surgery. When asked to describe these events, deaths of loved ones, marital problems, health issues, children serving in Iraq, and losses of jobs and pets were cited. Negative life events have been proposed as possible barriers to success, but the current study did not find this. However, because the definition of a negative life event in subjective and wide-ranging, it should not be surprising that most subjects in both groups reported experiencing at least one within the last five years. It may be beneficial for future researchers to inquire about specific, single issues, such as marital problems.

\section{LIMITATIONS}

The present investigation did have some limitations. For twenty-eight of the forty subjects $(70 \%)$, current weight was self-reported. It is possible that these self-reported weights were not correct, which would affect study results. In addition, previous research has demonstrated underreporting of intake among obese populations, and this could have occurred here as well. Further, respondents may not have been truthful in answering other survey questions and may have provided answers that were socially acceptable but not necessarily accurate. A final limitation of the current study is that the patients participating in the research were from one medical center, and therefore the results may not be applicable to those at other facilities. 


\section{IMPLICATIONS FOR FUTURE}

Gastric bypass surgery is not foolproof. Some patients simply fail to lose a significant amount of weight, or regain weight after surgery. In the current study, failure rate was $50 \%$. Although this study did not find any statistically significant differences between successful and unsuccessful patients five years after gastric bypass surgery, these results should not hinder further investigation or frustrate health professionals who advocate for lifestyle modification behaviors such as reducing portions or seeking followup. Clearly, there are differences between successful and unsuccessful patients with regards to energy balance, and there is a critical need to investigate these factors in order to improve long-term outcomes.

The study does direct attention at the important role that dietetics professionals can and should play after surgery. There is evidence that patients forget pre-surgery nutrition education ${ }^{26}$, which the current study also revealed. For example, two subjects were unable to identify any foods that contain protein. Subjects also expressed some confusion over follow-up post-surgery: One unsuccessful subject noted that her surgeon told her she never needed to come back once she lost weight, and another successful subject said she felt "cast out into the wind" after surgery. Since gastric bypass surgery requires lifelong changes to behavior, patient should be directed to dietetics professionals not only in the months following surgery, but also on an ongoing basis in the long-term.

It is possible that the current investigation was not able to adequately measure intake differences between the groups, and future studies might benefit from a food frequency component or other measures of intake. Another factor that the current study 
did not examine was weight regain. Many subjects volunteered that they had regained some or all of the weight they initially lost after surgery. Therefore, it may be helpful to study when weight regain typically happens for these patients and whether particular behaviors or events trigger this regain. Though the current study asked only about follow-up with professionals other than their physician, asking subjects about follow-up with their surgeon or physician may also yield differences. While the follow-up rate for gastric bypass surgery is $60-80$ percent at one year, the drop off seen over time may be associated with less success ${ }^{4 !}$.

Finally, future researchers may want to explore the concept of personal motivation. Perhaps there is a discrepancy in the level of self-efficacy between the successful and unsuccessful patients. If some patients believe they have the ability to lose weight and maintain the loss, they may be more likely to be successful in the longterm. Asking patients to rate their level of confidence as well as the level of importance of losing weight and maintaining the loss may uncover importance differences. 


\section{BIBILIOGRAPHY}

1. Flegal KM, Carroll MD, Ogden CL, Johnson CL. Prevalence and trends in obesity among US adults, 1999-2000. JAMA. 2002;288:1723-1727.

2. Hedley A. Prevalence of Overweight and Obesity Among US Children, Adolescents, and Adults, 1999-2002. JAMA. 2004;291:23:2847-2850.

3. Fontaine KR, Redden DT, Wang C, Westfall AO, Allison DB. Years of life lost due to obesity. JAMA. 2003;289:2:187-193.

4. Olshansky SJ, Passaro DJ, Hershow RC, et al. A potential decline in life expectancy in the United States in the $21^{\text {st }}$ century. $N$ Engl $J$ Med. 2005;352:11:1138-1145.

5. Raebel MA, Malone DC, Conner DA, Xu S, Porter JA, Lanty FA. Health services use and health care costs of obese and nonobese individuals. Arch Intern Med. 2004; 164:2135-2140.

6. Wee CC, Phillips RS, Legedza ATR et al. Health care expenditures associated with overweight and obesity among US adults: Importance of age and race. Am J Public Health. 2005;95:1:159-165.

7. Sjostrom LV. Mortality of severely obese subjects. Am J Clin Nutr. 1992;55: $516 \mathrm{~S}-523 \mathrm{~S}$.

8. Tsai AG and Wadden TA. Systematic review: An evaluation of major commercial weight loss programs in the United States. Ann Intern Med. 2005;142:1:56-66.

9. U.S. Department of Health and Human Services, National Institutes of Health NIH Publication No. 01-4006 Dec. 2001. Available from: www.http://www.niddk.nih.gov/health/nutrit/pubs/gastric/gastricsurgery.htm. Accessed August 25, 2004.

10. Kral G. Selection of patients for anti-obesity surgery. International Journal of Obesity. 2001;25: S107-S112.

11. Hsu L et al. Nonsurgical factors that influence the outcome of bariatric surgery: A review. Psychosom Med. 1998;60:338-346. 
12. Balsiger BM, Luque-De Leon E, Sarr MG. Surgical treatment for obesity: Who is an appropriate candidate? Mayo Clin Proc. 1997;72:551-558.

13. Anonymous. NIH Conference. Gastrointestinal surgery for severe obesity: National Institutes of Health consensus development conference statement. Am J Clin Nutr. 1992;55:615S-619S.

14. Livingston EH. Hospital costs associated with bariatric procedures in the United States. Am J Surg. 2005;190:816-820.

15. Buchwald H, Avidor Y, Braunwald E, Pories W, Fahrback K, Schoelles K. Bariatric surgery: A systematic review and meta-analysis. JAMA. 2004;292:17241737.

16. Mitchell JE, Lancaster KL, Burgard MA, et al. Long-term follow-up of patients' status after gastric bypass. Obesity Surgery. 2001;11:464-468.

17. Cunningham E and Marcarson W. Surgical treatment for obesity. $J$ Am Diet Assn. 2000;100:9:1056.

18. MacLean LD, Rhode BM, Nohn CW. Late outcome of isolated gastric bypass. Ann Surg. 2000;231:524-528.

19. Knol JA. Management of the problem patient after bariatric surgery. Gastroenterol Clin North Am. 1994;2:345-369.

20. Cowan GWM and Buffington CK. Significant changes in blood pressure, glucose, and lipids with gastric bypass surgery. World J Surg.1998;22;987-992.

21. Rand CSW and Macgregor AMC. Morbidly obese patients' perceptions of social discrimination before and after surgery for obesity. South Med J. 1990;83:12:1390-1395.

22. Rand CSW and Macgregor AMC. Successful weight loss following obesity surgery and the perceived liability of morbid obesity. International Journal of Obesity. 1991;15:577-597.

23. Hafner RJ, Watts JM, Rogers J. Quality of life after gastric bypass for morbid obesity. International Journal of Obesity. 1991:15:555-560.

24. Brolin RE. Critical analysis of results: Weight loss and quality of data. Am J Clin Nutr. 1992;55:577S-581S.

25. Sjostrom L, Lindross AK, Peltonen $M$ et al. Lifestyle, diabetes, and 
cardiovascular risk factors 10 years after bariatric surgery. $N$ Engl JMed. 2004;351:2683-2693.

26. Benotti PN and Forse A. The role of gastric surgery in the multidisciplinary management of severe obesity. Am J Surg. 1995;169:361-367.

27. Hafner RJ and Rogers J. Husbands' adjustment to wives' weight loss after gastric restriction for morbid obesity. International Journal of Obesity. 1990;14:10691078.

28. Hsu LKG, Sullivan SP, Benotti PN. Eating disturbances and outcome of gastric bypass surgery: A pilot study. Int J Eat Disord. 1997;21:4:385-390.

29. Lavery MA and Loewy JW. Identifying predictive variables for long-term weight change after participation in a weight loss program. $J$ Am Diet Assn. 1993;93:1017-1024.

30. Cook CM and Edwards C. Success habits of long-term gastric bypass patients. Obesity Surgery. 1999;9:80-82.

31. Stocker DJ. Management of the bariatric surgery patient. Endocrinol Metab Clin North Am. 2003;32:437-457.

32. Madan AK and Tichansky DS. Patients postoperatively forget aspects of preoperative patient education. Obesity Surgery. 2005;15:1066-1068.

33. Herpertz S, Kielmann R, Wolf AM, Hebebrand J, Senf W. Do psychosocial variables predict weight loss or mental health after obesity surgery? A systematic review. Obes Res. 2004;12:1554-1569.

34. Klem ML, Wing RR, McGuire MT, Seagle HM, Hill JO. A descriptive study of individuals successful at long-term maintenance of substantial weight loss. Am J Clin Nutr. 1997;66:239-246.

35. Zemel M, Thompson W, Milstead A, Morris K, Campbell P. Calcium and dairy acceleration of weight and fat loss during energy restriction in obese adults. Obesity Research. 2004;12:582-590.

36. Zemel MB, Richards J, Milstead A, Campbell P. Effects of calcium and dairy on body composition and weight loss in African-American adults. Obesity Research. 2005;13:7:1218-1226.

37. Eck Clemens LH, Slawson DL, Klesges RC. The effect of eating out on dining quality in premenopausal women. J Am Diet Assn. 1991; 99:4:442-444. 
38. U.S. Department of Health and Human Services. U.S. Department of Agriculture. Dietary Guidelines for Americans, 2005. Available at: http://www.healthierus.gov/dietaryguidelines/. Accessed April 25, 2005

39. Wing R and Hill J. Successful weight loss maintenance. Annu Rev Nutr. 2001;21:323-341.

40. Wardé-Kamar J, Rogers M, Flancbaum L, Laferrère B. Calorie intake and meal patterns up to 4 years after roux-en-y gastric bypass surgery. Obesity Surgery. 2004; 14:1070-1079.

41. Shen R, Dugay G, Rajaram K, Cabrera I, Siegel N, Ren CJ. Impact of patient follow-up on weight loss after bariatric surgery. Obesity Surgery. 2004;14:514519. 
APPENDIX A

\section{RESULTS}




\begin{tabular}{|l|c|}
\hline \multicolumn{1}{|c|}{ Reasons for incomplete questionnaires } & n \\
\hline Phone number disconnected or unlisted & 35 \\
\hline Did not respond after five attempts & 16 \\
\hline Not interested in participating & 4 \\
\hline Ineligible for study & 1 \\
\hline
\end{tabular}

The investigator attempted to contact 97 individuals by mail and phone for the study during the months of October 2005 through February 2006. Forty-five subjects were accessible and contacted. Forty-one agreed to complete the study, which is a response rate of forty-two percent of the total sample and sixty-five percent of the accessible sample. The investigator was unable to contact 35 subjects because their phone numbers were disconnected or unlisted. Sixteen subjects did not respond after five attempts at contact. Four reported not being interested in participating, and one was not eligible because she did not have gastric bypass surgery.

Table 1. Summary of incomplete questionnaires

\begin{tabular}{|l|l|c|}
\hline Descriptive variable & & Value \\
\hline Age (years) & Mean & 50.5 \\
\hline & Range & $28-66$ \\
\hline Gender & Female $(\mathrm{n})$ & 35 \\
\hline & Male $(\mathrm{n})$ & 5 \\
\hline Pre-surgery weight $(\mathrm{lbs})$ & Mean & 330.7 \\
\hline & Range & $219-495$ \\
\hline Post-surgery weight $(\mathrm{lbs})$ & Mean & 236.2 \\
\hline & Range & $139-500$ \\
\hline Pre-surgery BMI $\left(\mathrm{kg} / \mathrm{m}^{2}\right)$ & & 54.0 \\
\hline Post-surgery BMI $\left(\mathrm{kg} / \mathrm{m}^{2}\right)$ & & 38.7 \\
\hline
\end{tabular}

The subjects ( 35 female and 5 male) had a mean age of 50.5, with a range of 28-66. Their mean pre-surgery weight was 330.7 pounds, with a range of $219-495$. Their mean postsurgery weight was 236.2 pounds, with a range of 139-500. Their mean pre-surgery Body Mass Index (BMI) was $54.0 \mathrm{~kg} / \mathrm{m}^{2}$, and their mean post-surgery BMI was 38.7 .

Table 2. Descriptive profile of the subjects 


\begin{tabular}{|l|c|c|}
\hline & Successful $^{*}$ & Unsuccessful $^{* *}$ \\
\hline Mean pre-surgery weight $(\mathrm{lbs})$ & 330.7 & 330.7 \\
\hline Mean pre-surgery BMI $\left(\mathrm{kg} / \mathrm{m}^{2}\right)$ & 53.4 & 54.6 \\
\hline Mean post-surgery weight $(\mathrm{lbs})$ & 196.1 & 275.7 \\
\hline Mean post-surgery BMI $\left(\mathrm{kg} / \mathrm{m}^{2}\right)$ & 31.8 & 45.5 \\
\hline
\end{tabular}

${ }^{*} \mathrm{n}$ successful $=20 ;{ }^{*}$ n unsuccessful $=20$

Success was defined as a loss of at least 50 percent of excess pre-surgery weight and maintenance of the loss.

Table 3. Mean pre- and post-surgery body weight and Body Mass Index (BMI) of successful and unsuccessful subjects

\begin{tabular}{|c|c|c|}
\hline Guideline & $\begin{array}{l}\text { Successful* } \\
\text { n (\%) }\end{array}$ & $\begin{array}{c}\text { Unsuccessful*** } \\
\text { n (\%) }\end{array}$ \\
\hline Frequent meals ( $\geq 4 /$ day $)^{1}$ & $10(50)$ & $4(20)$ \\
\hline Frequent protein $(\geq 3 / \text { day })^{2}$ & $10(50)$ & $7(35)$ \\
\hline Prenatal multivitamin 3 & $7(35)$ & $4(20)$ \\
\hline Avoidance of sweets ${ }^{4}$ & $5(25)$ & $2(10)$ \\
\hline
\end{tabular}

$*_{\mathrm{n}}$ successful $=20 ; * *^{\mathrm{n}}$ unsuccessful $=20$

Success was defined as a loss of at least 50 percent of excess pre-surgery weight and maintenance of the loss.

${ }^{1}$ Chi-Square with 6 degrees of freedom $=8.599 ; p=.197$

${ }^{2}$ Chi-Square with 4 degrees of freedom $=5.343 ; \mathrm{p}=.254$

${ }^{3}$ Chi-Square with 2 degrees of freedom $=1.247 ; p=.536$

${ }^{4}$ Chi-Square with 1 degree of freedom $=1.558 ; \mathrm{p}=.212$

Table 4. Summary of adherence to post-surgery nutrition guidelines among subjects 


\begin{tabular}{|l|c|c|c|}
\hline \multicolumn{1}{|c|}{ Intake Variable } & $\begin{array}{c}\text { Successful* } \\
\mathbf{n}(\mathbf{\%})\end{array}$ & $\begin{array}{c}\text { Unsuccessful*** } \\
\mathbf{n ~ ( \% )}\end{array}$ \\
\hline Number of meals $^{1}$ & $1-3 /$ day & $10(50)$ & $16(80)$ \\
\hline & 4 or more & $10(50)$ & $4(20)$ \\
\hline Length of time to eat a meal $^{2}$ & $0-19$ minutes & $16(80)$ & $15(75)$ \\
\hline & 20 or more & $4(20)$ & $5(25)$ \\
\hline Frequency of protein intake $^{3}$ & $1-2$ sources/day & $8(40)$ & $12(60)$ \\
\hline & 3 or more/day & $10(50)$ & $7(35)$ \\
\hline Frequency of calcium intake $^{4}$ & $0-1$ sources/day & $8(42.1)$ & $12(60)$ \\
\hline & 2 or more & $11(57.9)$ & $8(40)$ \\
\hline Frequency of dining out $^{5}$ & Daily & $1(5)$ & $2(10)$ \\
\hline & At least twice/week & $12(60)$ & $14(70)$ \\
\hline & Twice/month or less & $7(35)$ & $4(25)$ \\
\hline Incorporation of sweets $^{6}$ & Yes & $15(75)$ & $18(90)$ \\
\hline & No & $5(25)$ & $2(10)$ \\
\hline
\end{tabular}

${ }^{*} \mathrm{n}$ successful $=20 ; *$ n unsuccessful $=20$

Success was defined as a loss of at least 50 percent of excess pre-surgery weight and maintenance of the loss.

${ }^{1}$ Chi-Square with 6 degrees of freedom $=8.599 ; p=.197$

${ }^{2}$ Chi-Square with 2 degrees of freedom $=1.293 ; \mathrm{p}=.524$

${ }^{3}$ Chi-Square with 4 degrees of freedom $=5.343 ; p=.254$

${ }^{4}$ Chi-Square with 3 degrees of freedom $=2.776 ; p=.427$

${ }^{5}$ Chi-Square with 4 degrees of freedom $=1.762 ; p=.779$

${ }^{6}$ Chi-Square with 1 degree of freedom $=1.558 ; \mathrm{p}=.212$

Subjects were asked how many meals (including "mini meals") they consumed each day. Fifty percent of successful subjects $(\mathrm{n}=10)$ and twenty percent of unsuccessful subjects $(n=4)$ reported eating four or more. The majority of successful $(80$ percent; $n=16)$ ) and unsuccessful ( 75 percent; $n=14$ ) of subjects reported taking 19 or fewer minutes to eat a meal. Fifty percent of successful subjects $(n=10)$ and thirty-five percent of unsuccessful subjects $n=7$ ) reported eating three or more protein sources per day. Thirty-five percent of successful subjects $(n=7)$ and twenty-five percent of unsuccessful subjects $(n=5)$ reported eating out twice a month or less. The majority of successful subjects ( 75 percent; $n=15$ ) and unsuccessful subjects ( 90 percent; $n=18$ ) reported incorporating sweets into their diets.

Table 5. Intake of meals, protein, calcium, and sweets among subjects 


\begin{tabular}{|l|c|l|c|}
\hline \multicolumn{1}{|c|}{ Successful* } & \multicolumn{1}{c|}{$\begin{array}{c}\text { Times } \\
\text { mentioned }\end{array}$} & \multicolumn{1}{|c|}{ Unsuccessful** } & $\begin{array}{c}\text { Times } \\
\text { mentioned }\end{array}$ \\
\hline Chips/Snack Food & 7 & Chips/Snack Food & 7 \\
\hline Popcorn & 5 & Cheese and crackers & 6 \\
\hline Yogurt & 4 & Pretzels & 5 \\
\hline Vegetables & 4 & Sweets & 5 \\
\hline $\begin{array}{l}\text { Protein (such as } \\
\text { cheese, meat, eggs) }\end{array}$ & 4 & Fruit & 4 \\
\hline
\end{tabular}

${ }^{*} \mathrm{n}$ successful $=20 ;{ }^{* *} \mathrm{n}$ unsuccessful $=20$

Success was defined as a loss of at least 50 percent of excess pre-surgery weight and maintenance of the loss.

Table 6. Snacks consumed by subjects

\begin{tabular}{|c|c|c|}
\hline Level of multivitamin dosage & Successful n (\%) & Unsuccessful n (\%) \\
\hline Take at recommended level & $7(35)$ & $4(20)$ \\
\hline Not at recommended level & $9(45)$ & $12(60)$ \\
\hline Don't take vitamins & $4(20)$ & $4(20)$ \\
\hline \multicolumn{3}{|l|}{ Usage of additional supplements ${ }^{2}$} \\
\hline Yes & $11(55)$ & $12(60)$ \\
\hline No & $9(45)$ & $7(35)$ \\
\hline
\end{tabular}

$*_{n}$ successful $=20 ; * *$ unsuccessful $=20$

Success was defined as a loss of at least 50 percent of excess pre-surgery weight and maintenance of the loss.

${ }^{1}$ Chi-Square with 2 degrees of freedom $=1.247 ; p=.536$

${ }^{2}$ Chi-Square with 1 degree of freedom $=.268 ; p=.605$

Thirty-five percent of successful subjects $(n=7)$ and 20 percent of unsuccessful subjects $(n=4)$ report taking a daily multivitamin at the recommended level, typically a prenatal vitamin. Twenty-percent of both groups $(\mathrm{n}=8)$ reported taking no multivitamin. Fifty-five percent of successful subjects $(n=11)$ and sixty percent of unsuccessful subjects $(n=12)$ reported taking additional supplements.

Table 7. Intake of multivitamins and supplements 


\begin{tabular}{|l|c|}
\hline \multicolumn{1}{|c|}{ Supplement } & n \\
\hline Iron & 13 \\
\hline Calcium & 13 \\
\hline B12 & 8 \\
\hline Potassium & 5 \\
\hline Vitamin E & 5 \\
\hline Vitamin C & 4 \\
\hline
\end{tabular}

The most common supplements reported by subjects were iron $(\mathrm{n}=13)$ and calcium $(n=13) . B 12(n=8)$, potassium $(n=5)$, vitamin $E(n=5)$ and vitamin $C(n=4)$ were also reported.

Table 8. Supplements taken by subjects

\begin{tabular}{|c|c|c|}
\hline Beverage & $\begin{array}{c}\text { Successful }^{*} \\
\text { (glasses/day) }^{*}\end{array}$ & $\begin{array}{c}\text { Unsuccessful }^{* *} \\
\text { (glasses/day) }^{*}\end{array}$ \\
\hline Water $^{1}$ & 4.9 & 4.1 \\
\hline Regular Soda $^{2}$ & .2 & .6 \\
\hline Diet soda $^{3}$ & 1.2 & 1.5 \\
\hline Juice $^{4}$ & .2 & .3 \\
\hline Beer $^{5}$ & .1 & 0 \\
\hline Alcohol $^{6}$ & 0 & .2 \\
\hline Wine & 0 & 0 \\
\hline
\end{tabular}

${ }^{*}$ n successful $=20 ;{ }^{* *}$ unsuccessful $=20$

Success was defined as a loss of at least 50 percent of excess pre-surgery weight and maintenance of the loss.

${ }^{1}$ Chi-Square with 13 degrees of freedom $=13.000 ; p=.448$

${ }^{2}$ Chi-Square with 5 degrees of freedom $=5.273 ; p=.384$

${ }^{3}$ Chi-Square with 8 degrees of freedom $=6.000 ; p=.647$

${ }^{4}$ Chi-Square with 4 degrees of freedom $=2.366 ; p=.669$

${ }^{5}$ Chi-Square with 1 degree of freedom $=1.026 ; p=.311$

${ }^{6}$ Chi-Square with 1 degree of freedom $=1.026 ; p=.311$

The mean water consumption among successful subjects was 4.9 glasses per day, and 4.1 glasses per day for unsuccessful subjects. Successful subjects consumed .2 glasses of regular soda, 1.2 glasses diet soda, .2 glasses juice, .1 glasses beer, and 0 glasses alcohol or wine per day. Unsuccessful subjects too in .6 glasses regular soda, 1.5 glasses diet soda, .3 glasses juice, 0 glasses beer, .2 glasses alcohol, and 0 glasses wine per day.

Table 9. Mean beverage consumption among subjects 


\begin{tabular}{|c|c|c|c|}
\hline & & Successful n (\%) & Unsuccessful n (\%)** \\
\hline Number who exercise & & $11(55)$ & $8(40)$ \\
\hline \multirow[t]{4}{*}{ Exercise frequency $^{2}$} & Never & $10(50)$ & $12(60)$ \\
\hline & Once/week & $0(0)$ & $4(20)$ \\
\hline & 2-3 times /week & $6(30)$ & $2(10)$ \\
\hline & Daily & $4(20)$ & $2(10)$ \\
\hline \multirow[t]{3}{*}{ Duration of exercise $^{3}$} & $0-15$ minutes & $2(18.2)$ & $1(12.5)$ \\
\hline & 16-30 minutes & $7(63.6)$ & $5(62.5)$ \\
\hline & $31-60$ minutes & $2(18.2)$ & $2(25)$ \\
\hline
\end{tabular}

$*^{*}$ successful $=20 ; * * n$ unsuccessful $=20$

Success was defined as a loss of at least 50 percent of excess pre-surgery weight and maintenance of the loss.

${ }^{1}$ Chi-Square with 1 degree of freedom $=.902 ; p=.342$

${ }^{2}$ Chi-Square with 3 degrees of freedom $=6.848 ; p=.077$

${ }^{3}$ Chi-Square with 2 degrees of freedom $=.198 ; p=.906$

Fifty-five percent of successful subjects $(n=11)$ and forty percent of unsuccessful subjects $(n=8)$ reported exercising. Twenty percent of successful subjects $(n=4)$ and 10 percent of unsuccessful subjects $(n=2)$ reported exercising daily. Of the eleven successful subjects and eight unsuccessful subjects who exercised, 63.6 percent of successful $(n=7)$ and 62.5 percent of unsuccessful subjects reported exercising for 16-30 minutes.

Table 10. Exercise habits among subjects

\begin{tabular}{|l|c|}
\hline \multicolumn{1}{|c|}{ Exercise } & N \\
\hline Walking & 13 \\
\hline Exercise videos & 2 \\
\hline Exercise bike & 2 \\
\hline Work out at fitness center & 2 \\
\hline
\end{tabular}

Table 11. Types of exercises performed by subjects 


\begin{tabular}{|c|c|c|}
\hline Number of weeks & Successful n (\%) & Unsuccessful n $\mathbf{~ ( \% ) ~}^{*} *$ \\
\hline $2-4$ & $11(68.8)$ & $15(88.2)$ \\
\hline $6-8$ & $3(18.8)$ & $2(11.8)$ \\
\hline$>8$ & $2(12.5)$ & $0(0)$ \\
\hline
\end{tabular}

${ }^{*} \mathrm{n}$ successful $=20 ;{ }^{* *} \mathrm{n}$ unsuccessful $=20$

Success was defined as a loss of at least 50 percent of excess pre-surgery weight and maintenance of the loss.

Chi-Square with 4 degrees of freedom $=4.999 ; p=.287$

Subjects were asked how long they remained on the Step 2 diet, a pureed-foods diet prescribed after surgery. Eleven successful subjects ( 68.8 percent) and fifteen unsuccessful subjects ( 88.2 percent) reported spending $2-4$ weeks on the diet. Three successful subjects (18.8 percent) and two unsuccessful subjects (11.8 percent) reported spending 6-8 weeks on the diet. Seven subjects could not recall the length of time spent on the diet.

Table 12. Frequency of time spent on Step 2 diet after surgery

\begin{tabular}{|l|c|c|}
\hline Medication changes & Successful $\mathbf{n}(\boldsymbol{\%})^{*}$ & ${\text { Unsuccessful } \mathbf{n}(\boldsymbol{\%})^{* *}}^{* *}$ \\
\hline Yes & $13(68.4)$ & $17(85)$ \\
\hline No & $6(31.6)$ & $3(15)$ \\
\hline
\end{tabular}

${ }^{*} \mathrm{n}$ successful $=20 ; * * \mathrm{n}$ unsuccessful $=20$

Success was defined as a loss of at least 50 percent of excess pre-surgery weight and maintenance of the loss.

Chi-Square with 1 degree of freedom $=1.509 ; \mathrm{p}=.219$

Of successful subjects, 68.4 percent $(n=13)$ reported changes in their medication since surgery. Eighty-five percent of unsuccessful subjects $(n=17)$ reported changes in medication.

Table 13. Changes in medication since surgery 


\begin{tabular}{|l|c|c|}
\hline Follow-up & Successful n (\%) & Unsuccessful n (\%) $\mathbf{~}^{* *}$ \\
\hline Yes & $11(55)$ & $9(45)$ \\
\hline No & $9(45)$ & $11(55)$ \\
\hline
\end{tabular}

${ }^{*} \mathrm{n}$ successful $=20 ; *$ n unsuccessful $=20$

Success was defined as a loss of at least 50 percent of excess pre-surgery weight and maintenance of the loss.

Subjects were asked whether they had sought any type of follow up since surgery (not including visits with their physician), such as appointments with a registered dietitian or attendance in a support group. Fifty-five percent of successful subjects $(\mathrm{n}=11)$ and fortyfive percent of unsuccessful subjects $(n=9)$ reported seeking follow-up.

Table 14. Numbers of subjects seeking follow up after surgery

\begin{tabular}{|l|c|c|}
\hline Level of satisfaction & Successful n (\%)* & Unsuccessful n (\%)*** \\
\hline Extremely satisfied & $10(50)$ & $5(25)$ \\
\hline Satisfied & $8(40)$ & $10(50)$ \\
\hline Somewhat satisfied & $0(0)$ & $3(15)$ \\
\hline Somewhat dissatisfied & $1(5)$ & $2(10)$ \\
\hline Dissatisfied & $0(0)$ & $0(0)$ \\
\hline Extremely dissatisfied & $1(5)$ & $0(0)$ \\
\hline
\end{tabular}

${ }^{*}$ n successful $=20 ; * n$ unsuccessful $=20$

Success was defined as a loss of at least 50 percent of excess pre-surgery weight and maintenance of the loss.

Chi-Square with 4 degrees of freedom $=6.222 ; p=.183$

Ninety percent of both subjects classified as successful $(n=18)$ and unsuccessful $(n=18)$ reported that they were extremely satisfied, satisfied, or somewhat satisfied with the nutrition education they received before surgery.

Table 15. Level of satisfaction with pre-surgery nutrition education 


\begin{tabular}{|l|c|c|c|}
\hline Factor & & Successful n (\%)* $^{*}$ & Unsuccessful n (\%) $^{* *}$ \\
\hline Negative events since surgery $^{\mathbf{1}}$ & Yes & $14(70)$ & $15(75)$ \\
\hline & No & $6(30)$ & $5(25)$ \\
\hline Complications after surgery $^{2}$ & Yes & $12(60)$ & $10(50)$ \\
\hline & No & $8(40)$ & $10(50)$ \\
\hline Adequate support after surgery $^{3}$ & Yes & $18(90)$ & $18(90)$ \\
\hline & No & $2(10)$ & $2(10)$ \\
\hline
\end{tabular}

${ }^{*}$ n successful $=20 ; * * n$ unsuccessful $=20$

Success was defined as a loss of at least 50 percent of excess pre-surgery weight and maintenance of the loss.

1 Chi-Square with 1 degree of freedom $=.125 ; \mathrm{p}=.723$

2 Chi-Square with 1 degree of freedom $=.404 ; p=.525$

3 Chi-Square with 1 degree of freedom $=.000 ; p=1.000$

Seventy percent of successful subjects $(n=14)$ and 75 percent of unsuccessful subjects $(n=15)$ reported experiencing negative life events, such as death of a loved one or a divorce, since surgery. Sixty-percent of successful subjects $(n=12)$ and 50 percent of unsuccessful subjects $(\mathrm{n}=10)$ reported having complications after surgery, such as infection or rehospitalization. Ninety percent of both groups (successful $n=18$; unsuccessful $n=18$ ) reported having an adequate amount of social support in their lives after surgery.

Table 16. Factors affecting quality of life after surgery 


\section{APPENDIX B}

GASTRIC REDUCTION OUTCOMES INTERVIEW QUESTIONNAIRE 


\section{Gastric Reduction Outcomes Interview Questionnaire}

Patient Name:

MRN\#:

Age:

Gender:

Patient provided verbal consent:

yes no date

\section{NUTRITION}

1. How many meals do you eat each day? 1 meal (1) __ 2 meals (2) __ 3 meals (3) __ 4 meals (4) __ 5-6 meals (5)

2. How long do you take to eat a meal?

0-9 minutes (1) 10-19 minutes (3) 20 minutes or more (5)

3. What high protein foods do you eat or drink most often?

4. How often?

1 source/day (1)

5 sources/day (5)

2 sources/day (2) 3 sources/day (3) 4 sources/day (4)

5. What kinds of vitamins do you take?

Don't take (1) _ _ Not at recommended level (3)___ Prenatal/equivalent (5)

6. What other kinds of supplements do you take?

7. What sources of high calcium foods/beverages do you eat and drink most often?
$0-1$ source/day (1) 2 sources/day (3) 3 sources/day $(5)$

\section{BEHAVIORS}

8. How long did you remain on the Step 2 diet post-surgery?
2 weeks (1)
4 weeks (2)
6 weeks (3)
8 weeks (4)

9. Have there been any changes in medication since surgery? _yes (1) no no (2)

If yes, explain

10. How often do you exercise? never (1) once/week (2) 2-3 times/week (3) daily (4) 
11. When you exercise, for how many minutes do you exercise? 0-15 minutes (1) 16-30 minutes (2) 31-60 minutes (3) $>60$ minutes (4)

12. What types of exercise do you do?

13. How many glasses of the following beverages do you drink each day?

Water Regular Soda Diet Soda Juice Beer Alcohol Wine

14. How often do you eat out in restaurants? daily (1) 2-3 times/week (2) once/week (3) never (4)

15. Do you incorporate sweets into your diet? YES $\mathrm{NO}$

If yes, what kinds?

16. What other types of snacks do you eat?

17. Besides appointments with your physician, have you sought any other type of followup (ex: a dietitian, other health care professional, or support groups in person or online?) no (1) _ yes (2)

If so, what type?

\section{SATISFACTION}

18. How satisfied were you with the nutrition education you received presurgically? Extremely dissatisfied (1)__ Dissatisfied (2)__ Somewhat dissatisfied (3) Somewhat satisfied (4) ___ Satisfied (5)__Extremely satisfied (6)

19. Current weight:

20. What do you feel have been barriers to weight loss?

\section{QUALITY OF LIFE}

21. Have you experienced any negative life events since your surgery (such as divorce, death of loved one, loss of job for self or spouse, etc.)? yes (1) no no (2)

If so, what type? 
22. Did you experience any problems or complications post-surgery? yes (1) no (2)

Dumping syndrome Pain Rehospitalization Other (explain:

23. Do you feel that you had an adequate amount of support in your life post-surgery? no (1) __ yes (2) 
APPENDIX C

CORRESPONDENCE 


\section{Initial Letter to Subjects Requesting Participation}

Date

Dear Mr./Ms.

Hello! We are writing to you because we are conducting a study on gastric bypass surgery. Our records indicate that you underwent gastric bypass surgery in 1999 , and we would like to get your help.

You are invited to take part in a brief interview about your experiences after surgery. The interviews will be held at The Ohio State University Center for Wellness and Prevention, located in the Martha Morehouse Medical Plaza (see enclosed directions). Parking is free. The interview will take less than $\mathbf{2 0}$ minutes and will take place in a confidential environment. You will not be identified in the study results, and no one will be able to connect you to the study.

As our way of thanking you for participating in this research, we'd like to offer you a free measurement of your resting metabolic rate - the number of calories you burn everyday. This is one of the latest developments in weight management, takes less than 10 minutes, and is completely noninvasive (it just involves breathing into the mouthpiece of a handheld device).

Knowing your individual metabolic rate offers you a powerful advantage. Patients who have had their metabolic rate measured have used the information to overcome frustrating weight loss plateaus, tailor their diet and fitness plan, and better understand the way their own body burns calories. The measurement, which is optional, will be given at the time of the interview. It normally costs $\$ 50$, but it's free if you agree to take part in the study.

If you'd like to participate in this study, please call (614) 218-6777 to schedule your interview (and, if you'd like, the free metabolic measurement). You may also email Kay Wolf at Wolf.4@osu.edu to arrange your interview. Interviews will take place on both weekday evenings and all day on Saturdays. If you have any questions about the study, please call Sally at (614) 218-6777, Shirley at (614) 293-2810 or Kay at (614) 292-8131.

It's our sincere hope that this research will help improve the quality of services to people like you, and we hope you'll choose to participate. We look forward to hearing from you!

Sincerely,

Sally Kuzemchak, R.D. Shirley Kindrick, Ph.D. R.D.

Graduate Student

Medical Dietetics
Adjunct Assistant Professor

Medical Dietetics
Kay Wolf, Ph.D. R.D.

Director

Medical Dietetics 


\section{Script for Follow-Up Phone Calls}

Good morning/afternoon/evening, Mr./Ms. . My name is and I am calling you from The Ohio State University.

A few weeks ago, you were sent a letter asking if you'd like to participate in a study on the experiences of patients after having gastric bypass surgery. I was calling to follow-up and see if you'd received it and whether you'd like to take part in the study.

(If they did not receive the letter) Within the next month, we'll be performing a survey of patients like yourself who underwent the surgery in 1999. The interview will take place at the Center for Wellness and Prevention (CWP) and will take less than 30 minutes to complete. You will not be identified in any way in the study results, and no one will be able to connect you to the study.

When you come in to take the survey, you'll also be able to get a free measure of your metabolism with the MedGem device. It's completely noninvasive and just involves breathing into a mouthpiece. The measurement, which you'll get at the time of the interview, is a $\$ 50$ value but is free if you agree to participate.

Are you willing to participate in our study?

(If yes) Schedule interview time

\section{Script for Answering Machine Message}

This message is for Mr./Ms. . This is

from The Ohio State University. I am calling to see if you would be willing to participate in an interview. The interview should take less than 20 minutes to complete. Please call me back at If I don't hear from you, I'll try giving you another call later this week. Thank you and have a good day. 


\section{Final Postcard Requesting Participation}

Dear

A few months ago, I sent you a letter asking if you'd like to participate in a study on the experiences of patients after having gastric bypass surgery. We haven't heard from you, so we wanted to give you a final chance to take part in this research.

We are conducting phone interviews that will take less than 10 minutes of your time. You will not be identified in any way in the study results, and no one will be able to connect you to the study.

If you'd like to participate, please call (614) 218-6777.

Thank you!

Sally Kuzemchak, R.D.

Graduate Student

The Ohio State University 